\title{
Vascular Development in the Zebrafish
}

\author{
Aniket V. Gore, Kathryn Monzo, Young R. Cha, Weijun Pan, and Brant M. Weinstein \\ Program in Genomics of Differentiation, Laboratory of Molecular Genetics, Section on Vertebrate \\ Organogenesis, NICHD, NIH, Bethesda, Maryland 20892 \\ Correspondence: flyingfish2@nih.gov
}

The zebrafish has emerged as an excellent vertebrate model system for studying blood and lymphatic vascular development. The small size, external and rapid development, and optical transparency of zebrafish embryos are some of the advantages the zebrafish model system offers. Multiple well-established techniques have been developed for imaging and functionally manipulating vascular tissues in zebrafish embryos, expanding on and amplifying these basic advantages and accelerating use of this model system for studying vascular development. In the past decade, studies performed using zebrafish as a model system have provided many novel insights into vascular development. In this article we discuss the amenability of this model system for studying blood vessel development and review contributions made by this system to our understanding of vascular development.

In recent years the zebrafish has emerged as an important vertebrate model system for studying vascular development. Zebrafish have a closed circulatory system, and the anatomical form of the developing vasculature, the processes used to assemble vessels, and the molecular mechanisms underlying vessel formation are highly similar to those in humans and other higher vertebrates (Isogai et al. 2001). Recent studies have also shown that the zebrafish possesses a bona fide lymphatic vascular system, making it useful for studying the formation of this distinct and separate vascular network as well. As a model system, the zebrafish offers unique advantages for studying vascular development in vivo (McKinney and Weinstein 2008; Isogai et al. 2009). Zebrafish are amenable to large-scale forward-genetic analysis, making them very useful for genetic screens for identifying vascular-specific mutations in novel genes regulating vascular development. Zebrafish embryos develop externally following fertilization, making them easily accessible to embryonic manipulation and imaging. The optical transparency of zebrafish embryos and larvae allows high-resolution optical imaging of blood vessels anywhere in the developing animal using transmitted light or fluorescent imaging techniques. The imaging advantages of the developing zebrafish have been further enhanced by the development of new techniques and tools for vascular imaging. These include a confocal microangiography technique for visualizing patent blood vessels, a complete anatomical description of the early vasculature of the zebrafish, generation of transgenic fish with fluorescently "tagged" vessels, and formulation of methods for long-term time-lapse

Editors: Michael Klagsbrun and Patricia D'Amore

Additional Perspectives on Angiogenesis available at www.perspectivesinmedicine.org

Copyright (C) 2012 Cold Spring Harbor Laboratory Press; all rights reserved; doi: 10.1101/cshperspect.a006684

Cite this article as Cold Spring Harb Perspect Med 2012;2:a006684 
A.V. Gore et al.

imaging of vascular development (Weinstein et al. 1995; Isogai et al. 2001; Lawson and Weinstein 2002b; Kamei et al. 2004). The small size of zebrafish embryos also allows them to receive sufficient oxygen for the first few days of development by passive diffusion alone, allowing other organs and tissue to continue to develop normally for several days in the absence of a functional cardiovascular system and greatly facilitating analysis of the specificity of vascular phenotypes caused by mutations or experimental manipulation.

Together, all of these features make the zebrafish an ideal system to study the development of the blood and lymphatic vascular systems. In this article, we briefly review what is known about how blood and lymphatic vessels are formed, patterned and remodeled during zebrafish development

\section{ORIGIN AND SPECIFICATION OF ENDOTHELIAL PRECURSORS}

As in other vertebrates, endothelial and hematopoietic cells in zebrafish embryos arise in close association with one another, and are thought to be derived from a common precursor. In zebrafish embryos, the two cell lineages develop in a spatially distinct manner from other vertebrates but are thought to rely on common genetic programs (Detrich et al. 1995). In avian and mammalian embryos, endothelial and hematopoietic cells develop in extraembryonic yolk sac blood islands, whereas in zebrafish embryos they develop in the intermediate cell mass derived from the ventral mesoderm (Fig. 1) (Moore and Owen 1965; Haar and Ackerman 1971; Detrich et al. 1995). However, early hematopoietic and endothelial cells in zebrafish and mammals express a common set of genes. Early expression of stem cell leukemia $(s c l)$ and fetal liver kinase-1/vascular endothelial growth factor receptor 2 ( $f l k 1 /$ vegfr 2 ) is required for endothelial and hematopoietic lineage formation in both mouse and zebrafish (Kabrun et al. 1997). Zebrafish carrying the cloche mutant also have defects in both hematopoiesis and endothelial cell development (Stainier et al. 1995). Mutations in genes required for proper ventral mesoderm formation, such as spadetail $(s p t)$ affect the formation of endothelial and hematopoietic cells, demonstrating the importance of the ventral mesoderm for this process (Thompson et al. 1998). However, it is not clear whether the defects observed in endothelial cell fate specification in these mesoderm mutants are caused by improper mesoderm formation or defects in the migration of the mesodermal layer. Together, the existence of genes required for both lineages, the fact that they develop in close association from primitive lateral mesoderm, and other data has led to the idea that there is a common precursor for both lineages. Although a bipotential precursor cell, referred to as the hemangioblast, has long been suspected to exist (Sabin 1920; Murray 1932), studies in mouse and zebrafish have only recently begun to provide some in vivo evidence for the existence of such a cell (Huber et al. 2004; Vogeli et al. 2006). Single-cell resolution fate mapping in zebrafish embryos through gastrulation showed that a minor proportion of endothelial and hematopoietic cells share a common bipotential precursor (Vogeli et al. 2006), although it is unclear to what extent this finding reflects a common early mesodermal hemangioblast precursor to both lineages or so-called "hemangiogenic endothelium" in the trunk capable of giving rise to definitive hematopoietic precursors. A great deal is known about the molecules and pathways controlling hematopoiesis, but this has been reviewed extensively elsewhere (see Paik and Zon 2010) and in this article we focus on the specification of endothelial cells.

Although at least some endothelial precursor cells (angioblasts) appear to become lineage-restricted during mid-gastrula stages, they begin to express endothelial-specific genes only during early somitogenesis (Kimmel et al. 1990; Fouquet et al. 1997). The early vascular expression of members of the ETS family of transcriptional regulators suggested they might be important for endothelial specification (Lelievre et al. 2001). ETS factors can induce expression of endothelial specific genes such as $f l k 1 / v e g f r 2$ and vascular endothelial cadherin $(\operatorname{vec} n)$, and loss of function for these factors 
Vascular Development in the Zebrafish

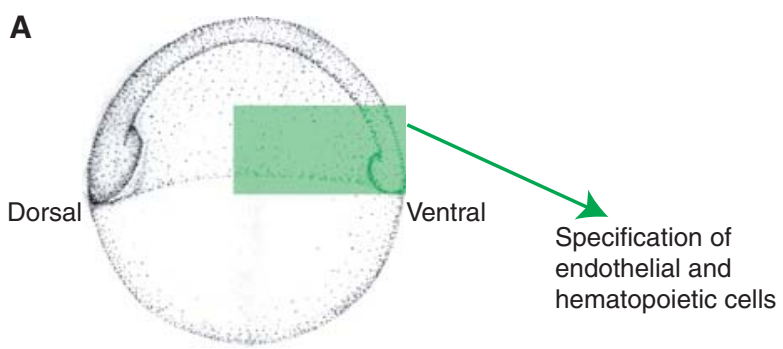

B

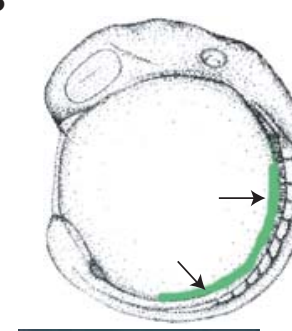

D

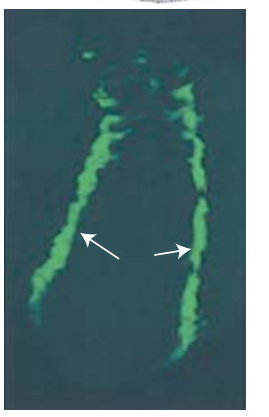

C

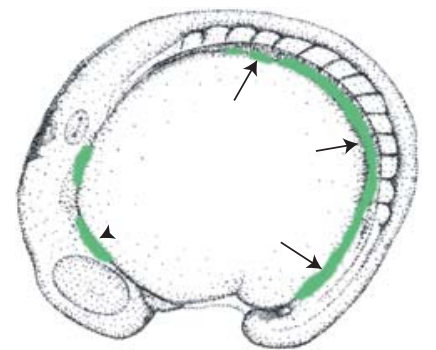

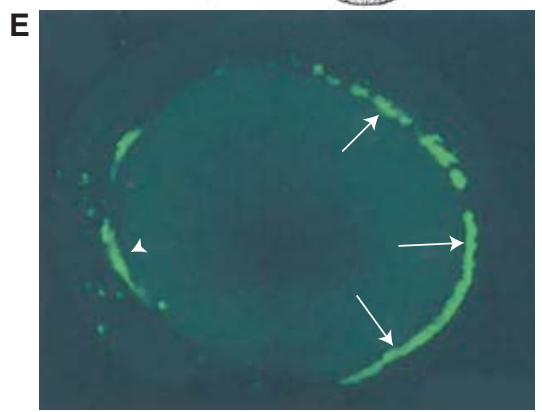

Figure 1. Endothelial cells are specified during early embryogenesis. (A) Schematic diagram of an early stage zebrafish embryo, with green boxed area indicating the region of ventral mesoderm in which endothelial precursors are specified. $(B, C)$ Schematic diagrams of 14 somite $(B)$ and 16 somite $(C)$ stage embryos shown in lateral view, with migrating angioblasts shown in green. $(D, E)$ Fluorescence micrographs of live embryos of comparable ages to $B$ and $C$, with green fluorescent protein expressed under the control of an endothelial-specific promoter. Arrows in $B-E$ show migrating caudal angioblasts in the posterior lateral plate mesoderm. Arrowheads in $C$ and $E$ show the position of rostral angioblasts in the anterior lateral mesoderm.

causes defects in endothelial cell behavior (Wakiya et al. 1996; Chen et al. 1997; Lelievre et al. 2000; Nakano et al. 2000). Loss of function of the ETS factor Etv2 (Etsrp71) in the mouse or frog and its ortholog, estrp, in zebrafish results in defects in vascular formation and hematopoietic differentiation (Sumanas and Lin 2006; Pham et al. 2007; Sumanas et al. 2008; Salanga et al. 2010). Although in vivo loss of function of the ETS factors ets1 or friend leukemia integration 1 ( fli1) does not cause significant defects in vascular development in mouse or zebrafish embryos, combinatorial knockdown of four vascular ETS factors, fli1a, fli1b, ets1, and ets1related protein (etsrp) in zebrafish leads to defects in endothelial cell specification and differentiation (Pham et al. 2007). It has also been reported that ETS factors function synergistically with other factors to specify endothelial cell fate, including members of the Forkhead (FOX) family of transcription factors (De Val et al. 2008) and KLF genes (Meadows et al. 2009). These observations suggest that the ETS factors play an important role in the initial specification of the endothelium through a combinatorial interaction with each other as 
A.V. Gore et al.

well as interactions with other transcriptional regulatory pathways, although it is unclear precisely how this regulation is coordinated. These observations suggest that the ETS factors play an important and cooperative role in the initial specification of the endothelium.

\section{FORMATION OF AXIAL VESSELS AND INITIAL SPECIFICATION OF ARTERIAL-VENOUS IDENTITY}

\section{Midline Migration of Angioblasts}

Once angioblasts have been specified from ventral-lateral mesoderm, they migrate to the embryonic midline directly above the underlying endoderm to form the primordia for the axial vessels, the dorsal aorta (DA) and posterior cardinal vein (PCV) (Fig. 1) (Lawson and Weinstein 2002b; Jin et al. 2005). These cells are positioned dorsal to the endodermal layer and ventral to the hypochord at the midline (Fouquet et al. 1997; Sumoy et al. 1997). The formation of the two major trunk axial vessels occurs by vasculogenesis, or the assembly of vessels de novo by coalescence of free angioblast progenitors. Vasculogenesis in zebrafish strongly resembles trunk axial vessel formation in other developing vertebrates, although in Xenopus the posterior cardinal vein initially forms as a bilateral pair of vessels whereas in avians and mammals the dorsal aorta and posterior cardinal vein both form initially as paired vessels (Drake and Fleming 2000; Vokes et al. 2004). In all vertebrates, paired axial vessels or their primordia eventually "zipper together" to form single tubes, although the timing of this varies in different species. Zebrafish represent one end of the spectrum, with single DA and PCV tubes present from the time that circulation initiates in the trunk (Fig. 2A,B) (Isogai et al. 2003). In Xenopus, persistent expression of BMP inhibitors from the midline notochord is required for the initial separation of the bilateral dorsal aortae (Bressan et al. 2009). It is unclear whether earlier extinguishing of the expression of these inhibitors permits formation of a single tube at an earlier stage in the zebrafish, although this seems a likely possibility. Studies in avians and mice also indicate that hedgehog signaling from endoderm may also play an important role during early vasculogenesis (Cleaver et al. 2000; Vokes and Krieg 2002). In zebrafish, the ventral endodermal layer is required for proper migration of the angioblasts to the midline, although this does not appear to be BMP-dependent (Jin et al. 2005). In both Xenopus and zebrafish a transient embryonic structure called the hypochord that is found just ventral to the midline notochord and just above the assembling dorsal aorta expresses vascular endothelial growth factor (vegf). Studies in Xenopus suggest that hypochord-derived soluble VEGF acts as a guidance molecule to direct the migration of angioblasts toward midline, although direct evidence establishing such a functional role is still lacking (Cleaver and Krieg 1998). A similar mechanism has been proposed for zebrafish embryos as well (Lawson and Weinstein 2002a).

\section{Specification of Arteries and Veins}

As noted above, the first embryonic vessels form by vasculogenesis, in which early mesodermderived precursor endothelial cells or angioblasts coalesce to form the primary vasculature including the dorsal aorta, cardinal vein, and primitive cranial vasculature (Roman et al. 2002). As these first vessels assemble, they concomitantly acquire arterial and venous identity (Fig. 2). The vasculature is fundamentally divided into two types of blood vessels, arteries and veins, and the acquisition of arterial-venous identity and the assembly of distinct networks of arterial and venous vessels are critical for the proper functioning of the circulatory system.

Classically, acquisition of arterial-venous (A-V) identity was thought to be directed by physiological parameters such as differences in blood flow and pressure that emerge in otherwise naive vascular plexuses as blood circulation begins. However, studies over the last fifteen years have shown that the endothelial cells lining arteries and veins are both functionally and molecularly distinct, and that genetic programs regulate the initial specification of these 

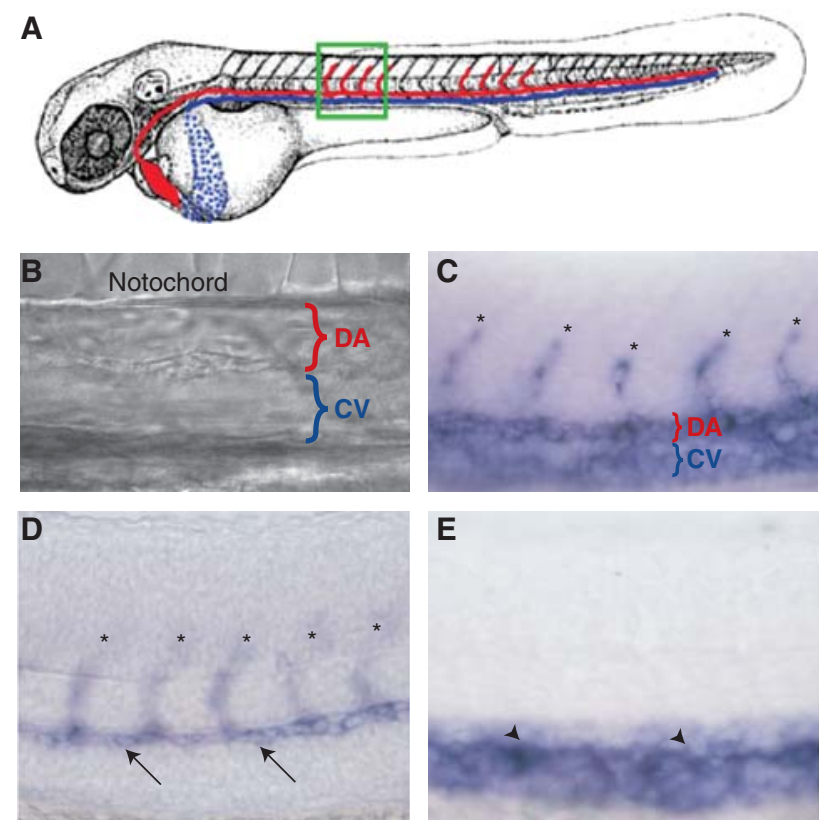

Figure 2. Formation of artery and vein fates. (A) Schematic diagram of a zebrafish embryo with dorsal aorta in red and cardinal vein in blue. The green boxed area shows the approximate region in the micrographs in $(B-E)$. $(B)$ bright-field DIC image showing position of dorsal aorta (DA) and cardinal vein (CV). Molecular markers distinguish arterial and venous endothelium even before the onset of circulation. $(C)$ vecdn expression marks $\mathrm{DA}, \mathrm{CV}$, and intersegmental vessel (ISV) sprouts (asterisks) in $24 \mathrm{hpf}$ animals. (D) dll4 is expressed in the DA (arrows) and ISV sprouts emanating from it (asterisks) but not in the CV at $24 \mathrm{hpf}$. (E) dab2 is expressed in the CV (arrowheads) but not in the DA or ISV sprouts at $24 \mathrm{hpf}$. Lateral views, anterior to the left.

two cell types in the developing embryo (Swift and Weinstein 2009). Probably the first conclusive evidence for a functionally important molecular distinction between arterial and venous endothelial cells came from work with ephrin and Eph genes in mice (Wang et al. 1998). Ephrin B2, a member of the ephrin family of membrane ligands, is expressed in arterial endothelial cells and is absent in venous endothelial cells, whereas the ephrinB2 receptor EphB4 is preferentially expressed in veins. The arterial- and venous-restricted expression of these genes is apparent very early in vascular development, before onset of circulation or even formation of lumenized vascular tubes, showing clearly that these initial expression patterns do not depend on flow. Targeted gene deletion of each member of this ligand-receptor pair resulted in similar cardiovascular abnormalities, showing that they are necessary for normal vascular development and likely directly interact with one another (Wang et al. 1998; Gerety and Anderson 2002). Interestingly, ephrin B2 mutant mice generated with $L a c Z$ "knocked in" to the ephrin B2 locus continue to express $L a c Z$ appropriately in the arterial compartment, indicating that initial specification of arterial or venous fate must involve additional factors upstream of ephrin B2 (Wang et al. 1998).

Studies performed on the zebrafish helped to uncover and dissect the functional roles of these upstream factors, resulting in the identification of a signaling cascade for arterial fate determination consisting of sequential hedgehog, vascular endothelial growth factor (vegf), and notch signaling. Notch signaling genes (Notch, Delta, Jagged, etc.) are expressed in arterial but not in venous endothelial cells and murine knockout studies showed that these 
A.V. Gore et al.

molecules play an important functional role in the vasculature (reviewed in Swift and Weinstein 2009). The nature of this functional role was not determined in the murine studies, but the arterial-specific expression of these genes suggested that they might be playing a role in artery formation. Functional studies in the zebrafish showed that Notch signaling acts to promote arterial differentiation at the expense of venous differentiation during vascular development (Lawson et al. 2001; Lawson et al. 2002; Lawson et al. 2003). Repression of notch signaling in zebrafish embryos resulted in loss of ephrinB2 expression from arteries and ectopic expansion of normally venous-restricted markers such as ephb4 and flt-4 into the arterial domain. Conversely, activation of Notch signaling suppressed expression of vein-restricted markers and promoted ectopic expression of ephrinB2 and other arterial markers in venous vessels.

Additional zebrafish studies showed that sonic hedgehog (shh) and vegf act upstream of Notch during arterial differentiation (Lawson et al. 2002; Lawson and Weinstein 2002a). Embryos lacking shh or vegf fail to express ephrin-B2 within their blood vessels, like embryos deficient in Notch signaling. Overexpression of shh promotes ectopic arterial vessel formation in the trunk, whereas overexpression of vegf suppresses expression of vein-restricted markers and results in expression of ephrinB2 and other arterial markers in venous vessels. By combining different methods for activating or repressing each of these signaling pathways in "molecular epistasis" experiments, a molecular pathway for arterial differentiation was deduced in which Shh activity induces expression of vegf in the somites, and that Vegf then activates Notch signaling in the endothelial cells of the developing dorsal aorta, promoting arterial differentiation. The importance of this pathway for $\mathrm{A}-\mathrm{V}$ fate determination was supported by work in other models. In mice, Shh induces expression of Vegf in ischemic limbs and induces new blood vessel growth in mice (Pola et al. 2001), whereas Vegf secreted by nerves promotes differentiation of adjacent arteries in embryonic skin (Mukouyama et al. 2002). Vegf also plays a role in postnatal arterial differentiation. Transgenic mice expressing VEGF-A in the heart show an increased percentage of arterial (ephrin B2 ${ }^{+}$) vessels in adult cardiac tissue compared to wild type mice (Visconti et al. 2002), and expression of VEGF-A in adult skeletal muscle causes an increase in arterial vessel density. Subsequent work in zebrafish and other model organisms has confirmed many of the features of this pathway and identified additional genes involved in arterial-venous fate determination including the downstream VEGF signaling effector phospholipase C $\gamma$-1 (plcg1) (Lawson et al. 2003), COUP-TFII, required for venous differentiation (You et al. 2005), as well as other genes including PI3 kinase, Erk, and receptor protein tyrosine phosphatase, Dep1 (Hong et al. 2006; Rodriguez et al. 2008).

Recent studies have identified other genes and pathways involved in morphogenesis of the dorsal aorta and cardinal vein in addition to the well-characterized HH-Notch-Vegf pathway. Three groups independently showed that the SRY-box containing Sox7 and Sox18 transcription factors play an important role during A-V morphogenesis. These Sox genes are expressed by developing dorsal aorta and vein, and loss of function studies showed that embryos depleted of Sox7/18 function develop A-V morphogenesis defects, including frequent shunts connecting the dorsal aorta and cardinal vein (Cermenati et al. 2008; Herpers et al. 2008; Pendeville et al. 2008). One of these studies also reported that Shh and Vegf signaling act upstream of and control Sox7 (Pendeville et al. 2008). Interestingly, another recent study has also suggested that there may be selective cell segregation required for proper A-V formation, with distinct steps of cell segregation into arterial and venous fates are controlled by different signaling pathways including VegfA, VegfC, Notch, and Ephrin B2 (Herbert et al. 2009).

Although the role for a genetically programmed molecular pathway regulating the early establishment of arterial-venous identity is well-established, other studies have shown that this identity is plastic and can be altered by vascular flow and other factors. Several studies using quail-chick grafting experiments to 
examine the plasticity of arterial-venous endothelial cell fate have shown that maintenance of differentiated A-V identity requires components of the vascular wall (Moyon et al. 2001; Othman-Hassan et al. 2001; le Noble et al. 2008). Portions of embryonic arteries or veins were grafted from quail donors at various stages of development into chick hosts, and the A-V identity of donor cells contributing to different host vessels was assessed using artery- or vein-specific molecular markers. Up until approximately E7 donor cells populate both types of vessels and assume the appropriate molecular identity, but after E7 this plasticity is progressively lost. However, isolated endothelial cells or isolated dissected endothelia were still plastic even in older vessels, suggesting that components of the vascular wall are necessary to maintain, or are sufficient to redirect, the arterial-venous identity of adjacent endothelial cells.

\section{FORMATION OF INTERSEGMENTAL VESSELS AND LUMENOGENESIS}

\section{ISV Formation and Role of Vegf/Vegfr Signaling}

Following initial formation of the primitive vasculature by vasculogenesis, most subsequent vessel formation during development takes place via angiogenesis - the formation of new vessels by budding growth from, or remodeling of, preexisting vessels. The intersegmental vessels (ISVs) of the trunk are among the first angiogenic vessels to form in all vertebrates. A two-step process for intersegmental vessel formation has been documented by time-lapse imaging of vessel development in transgenic zebrafish (Isogai et al. 2001). Following formation of the DA and PCV, a set of new sprouts emerges from the dorsal side of the DA and grows dorsally along vertical somite boundaries. The migration of these sprouts is very rapid and dynamic, with numerous filopodia-like cellular processes extending from the tips of the growing sprouts in all directions (Fig. 3A). As they reach the dorsal-lateral surface of the neural tube, the growing vascular segments branch rostrally and caudally, and then interconnect to form the dorsal longitudinal anastomotic vessel (DLAV). At the early stages the identity of all of these vessels is not defined, but as the vessels become interconnected and flow begins arterial-venous fate becomes established, likely in response to this flow (Isogai et al. 2003).

Zebrafish studies have shown that VEGF and Notch signaling is also important for the formation of the intersegmental vessels. VEGF-A is produced and secreted by the somites between which the ISV sprouts migrate, and loss of VEGFR-2 function inhibits ISV formation (Habeck et al. 2002). Reduction of downstream VEGF signaling via mutation of plcg1 (Lawson et al. 2003) or reduced vascular ETS transcription factor function in etsrp1 mutants (Sumanas and Lin 2006; Pham et al. 2007) also causes defects in ISV formation. The VEGFR-1 receptor also plays an important role during angiogenesis. Although VEGFR-2 signaling promotes growth of ISVs, studies from cultured endothelial cells indicate that the VEGFR-1 receptor, which has a high affinity for VEGF but a poor capacity for signaling, helps guide sprouting by dampening local VEGF levels and sharpening VEGF gradients for vessels to migrate along (Chappell et al. 2009). There is at present no direct evidence for such a role for VEGFR-1 during zebrafish intersegmental vessel development.

During ISV migration, the leading cell forms filopodial structures and guides the proximal cells to form a single intersegmental vessel. Typically three to five endothelial cells populate each ISV during early stages of its growth (Childs et al. 2002; Siekmann and Lawson 2007). Architecturally, how these cells are connected to one another and how they form single a seamless tube is still not fully understood (Blum et al. 2008).

\section{Specification of Tip and Stalk Cells and Keeping Them in Line}

Endothelial cells located at the most distal end of sprouts, termed "tip cells," have distinct gene expression profiles and behaviors and are critical for initiating and guiding sprouting 
A.V. Gore et al.
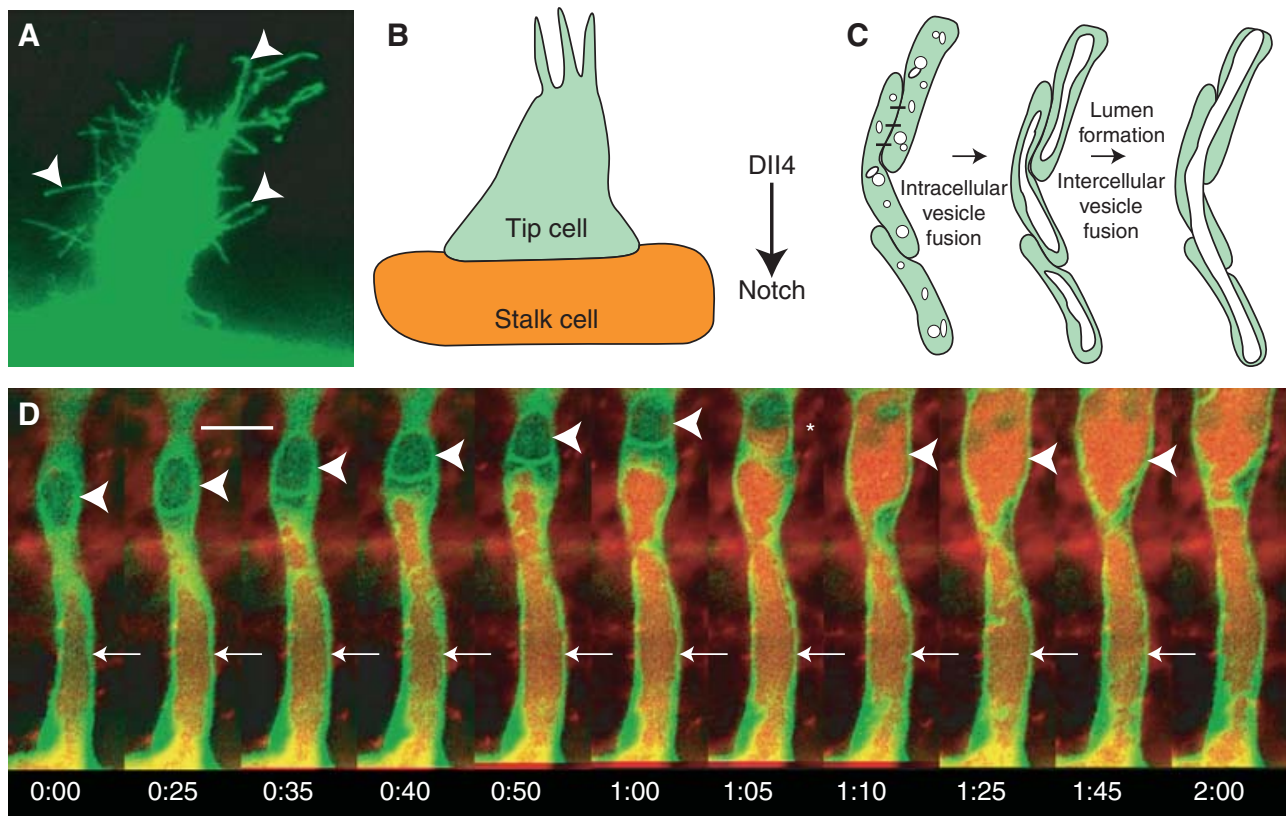

Figure 3. Development of intersegmental vessels. (A) Newly formed and growing intersegmental vessel sprout with multiple cellular processes (arrowheads). (B) Schematic diagram of tip and stalk cells; Dll4 expressed in tip cells activates Notch in adjacent endothelial cells to promote stalk cell identity. $(C)$ A model for intracellular and intercellular vesicle fusion during vascular lumenogenesis. $(D)$ Two-photon time-lapse imaging of a lumenizing trunk intersegmental vessel in a living $T g$ ( fli1:EGFP-cdc42wt $)^{y 48}$ transgenic animal injected intravascularly with $605 \mathrm{~nm}$ quantum dots. Quantum dots are transferred from the dorsal aorta to vacuolar compartments in proximal (arrows) and then more distal (arrowheads) intersegmental endothelial cells. In frame 1:05 the vacuole in the distal endothelial cell was captured in the process of filling with quantum dots from the proximal cell below (asterisk). For each time-lapse sequence the time from the first frame of each successive image is noted in hours:minutes. Scale bar $=20 \mu \mathrm{m}$. ( $D$, From Kamei et al. 2006; reprinted, with permission, from the author.)

and vessel growth in the developing vascular system (Gerhardt et al. 2003; Siekmann and Lawson 2007). These terminal motile endothelial cells extend long dynamic filopodial extensions that sense attractive and repulsive growth cues, and help direct the growth of vascular sprouts. The endothelial cells located behind the tip cells are denoted "stalk cells," and they make up the base of the sprout and serve to maintain the structure of the forming vessel. Regulation of the number of tip cells is essential for the proper patterning of the vasculature and is dictated by VEGF and Notch signaling through lateral inhibition of an angiogenic state in stalk cells. VEGFR-2 activation in the tip cells leads to an up-regulation of the Notch receptor Delta-like-4 (DLL4) and a subsequent up-regulation of Notch activity (internalization of Notch) in the neighboring stalk cells. Increased Notch activity promotes stalk cell behavior at the expense of tip cell behavior. Studies using a variety of different model systems showed the role of DLL4 in specifying tip cell is highly conserved from lower vertebrates like zebrafish to mammals (Fig. 3B) (Hellstrom et al. 2007; Siekmann and Lawson 2007; Suchting et al. 2007). Notch activation in the stalk cells suppresses VEGFR-3/FLT4 signaling and a proangiogenic fate (Siekmann and Lawson 2007; Tammela et al. 2008). In the developing mouse retina and zebrafish intersegmental vessels, loss of Notch signaling activity by either genetic loss of function or pharmacological inhibition 
of Notch signaling results in an increase in cells showing proangiogenic tip cell behavior, including migration, branching/filopodial extension, and tip cell specific gene expression (Hellstrom et al. 2007; Leslie et al. 2007; Siekmann and Lawson 2007).

During embryonic development major vascular highways form in defined patterns with anatomically reproducible and evolutionarily conserved positions. This highlights the fact that in addition to the proper specification of the number and position of tip cells, it is important that the migratory route of these leading cells be properly guided to achieve the stereotypic patterning of the vascular system. In the nervous system, migrating neuronal axons are guided by specific attractive or repulsive molecular cues received by "growth cones" at the distal end of the growing axon, and recent studies have shown that the same or similar cues are playing an analogous role in guiding growing vessels (Melani and Weinstein 2010). Tip cells of both growing blood vessels and axons express receptors for guidance molecules such as Semaphorins, Netrins, and Ephrins. The Semaphorin family of ligands and their Plexin receptors are key players in both neuronal pathfinding and intersegmental vessel patterning. In zebrafish and mice, type 3 Semaphorins are expressed in the central portion of the developing somites (but not along their boundaries) whereas the type 3 Semaphorin receptor PlexinD1 is expressed specifically in endothelial cells. In zebrafish, loss of PlexinD1 in out of bounds (obd) mutants, or PlexinD1 or Semaphorin 3a2 function via morpholino injection, causes dramatic mispatterning of these vessels, which are no longer restricted to growing along intersomitic boundaries (Childs et al. 2002; Torres-Vazquez et al. 2004). Targeted disruption of plexinD1 in mice causes similar defects in intersegmental vessel patterning (Gitler et al. 2004; Gu et al. 2005), showing that the role of Semaphorin signaling in intersegmental vessel patterning is conserved across vertebrate species. A recent report has also suggested that zebrafish Semaphorin 3E functions with the PlexinB2 receptor expressed on endothelial cells to promote sprouting of intersegmental vessels (Lamont et al. 2009).
Other neuronal guidance factors also appear to play important roles in the vasculature. Netrin 1 and its receptor, $\mathrm{UNC5B}$, are required for the proper vessel formation, although conflicting data exist as to whether netrin signaling plays a repulsive role ( $\mathrm{Lu}$ et al. 2004; Larrivee et al. 2007; Bouvree et al. 2008), an attractive role (Navankasattusas et al. 2008), or, potentially, both (Yang et al. 2007) in the developing vasculature. In addition to their role in arterialvenous specification (Herbert et al. 2009), ephrins are also implicated in vascular sprouting in zebrafish. Morpholino knockdown of ephrinB2 causes tip cells to decrease filopodial activity in intersegmental vessels consistent with the observation that ephrin signaling promotes angiogenic activity (Wang et al. 1998).

\section{Forming a Vascular Tube}

To form a functional circulatory system, the endothelial cells lining blood vessels must develop a continuous luminal space. There are many possible ways to form tubes, including wrapping up of or budding from an epithelial sheet, cavitation (elimination of the central cells in a cellular cylinder), and cord or cell hollowing, in which lumens form by creation of fluidfilled spaces between cells or within single cells, respectively (see Lubarsky and Krasnow 2003 for comprehensive review of biological tube formation). Cord or cell hollowing are now generally thought to be the primary mechanisms used to form vascular lumens. Early observations hinted at a role for intracellular vacuoles during vascular lumen formation. Similar observations were later made in vitro during some of the first endothelial cell culture experiments. Folkman and Haudenschild (Folkman and Haudenschild 1980) reported "longitudinal vacuoles" within endothelial cells cultured in three-dimensional collagen or fibrin matrices. They also noted that these vacuoles appeared to traverse cell boundaries and make connections with neighboring cells (Fig. 3C). Since these initial observations, a number of later studies have verified and extended these findings and led to a proposed model for lumen formation via intracellular vacuolation and 
A.V. Gore et al.

intercellular fusion of endothelial vacuoles (Bayless et al. 2000; Bayless and Davis 2002; Kamei et al. 2006). These in vitro studies have shown that lumen formation depends on the activity of signaling pathways controlled by integrins, Cdc42, and Rac, as well as various polarity complexes containing Pak2, Pak4, and Par3/Par6/PKÇ (Davis and Camarillo 1996; Bayless and Davis 2002; Koh et al. 2008, 2009). Although vascular lumen formation has been primarily studied in vitro using human umbilical vein endothelial cells (HUVEC) to form vessels in three-dimensional collagen gel cultures (Davis and Camarillo 1996; Bayless and Davis 2002; Koh et al. 2008, 2009), these studies have recently begun to be validated by studies using in vivo model systems, in particular the zebrafish.

Kamei et al. took advantage of the optical clarity of the developing zebrafish and recently developed methods for long-term time-lapse imaging (Kamei et al. 2004) to examine endothelial tube assembly in vivo (Kamei et al. 2006). They used two-photon time-lapse imaging of $\mathrm{Tg}$ (fli1:EGFP-cdc42wt) ${ }^{y 48}$ transgenic embryos to look at the dynamics of endothelial lumen formation in vivo. In these embryos, the cdc42wt-EGFP fusion protein preferentially localizes to pinocytic vacuolar structures as shown previously in cultured endothelial cells (Bayless and Davis 2002), whereas use of the fli1 promoter allows specific expression of the fusion protein within zebrafish endothelial cells (Lawson and Weinstein 2002a). Time-lapse imaging of intersegmental vessel lumen formation reveals that in vivo vacuolar dynamics in these developing vessels are very similar to what has been described in cultured ECs (Kamei et al. 2006). Vacuoles emerge, disappear, and coalesce to form larger vacuoles on a timescale of minutes and eventually, the merging vacuoles enlarge to create a luminal space that occupies most of the cell. To examine how vacuolar compartments within different ECs become linked to create a common endothelial tube, they injected nanometersize fluorescent beads (quantum dots or Qdots) into the dorsal aorta and examined the transfer of Qdots to adjacent developing intersegmental vessels. They observed serial transfer of the quantum dots from the dorsal aorta into the vacuolar lumens of first the proximal ISV EC and next into the more distal ECs. These results indicated that a continuous luminal space in intersegmental vessels emerges from the fusion of preformed intracellular vacuolar compartments in neighboring endothelial cells. These data support the previously proposed model for vascular lumen formation by intracellular and intercellular fusion of endothelial vacuoles (Fig. 3D).

Whether or not this mechanism is generalizable to other vessel types like larger caliber vessels that form from larger aggregates of endothelial cells remains to be determined. Analysis of transverse sections of $\mathrm{Tg}(f l k 1 \text { :EGFP })^{s 843}$ embryos suggests that these vessels may form through cord hollowing (Jin et al. 2005). Angioblasts initially aggregate at the midline to form a cord-like structure without any detectable cellcell junctions. Within hours, cell-cell junctions become apparent and the cells begin to elongate and subsequently a lumen appears with four to six angioblasts around its circumference. Parker et al. make similar observations but also note that, prior to morphological changes, substantial refinement of the tight junctions between angioblasts occurs. They further show that morpholino-mediated knockdown of EGF-like domain 7 (Egfl7), a putative secreted factor that is endothelial-specific, results in maintenance of tight junctions and failure of angioblasts to separate (Parker et al. 2004). Although these results do not provide definitive evidence that these vessels form tubes through a cord hollowing, this seems the most probable mechanism. A cord hollowing mechanism has also been proposed based on studies of the lumenization of the mouse aorta (Strilic et al. 2009). In addition, recent examination of cell junctions in zebrafish intersegmental vessels during lumen formation suggests that the endothelial cells of these vessels overlap extensively, as shown by localization of the tight junction marker ZO-1 and that some of the nascent luminal spaces form extracellularly from their earliest stages (Blum et al. 2008). VE-cadherin-containing adherens junctions at the 
overlapping regions also appear to provide for the proper polarization of cells within the intersegmental vessels, and this polarization is dependent on Moesin 1 function and is essential for stabilization of vessel lumens (Wang et al. 2010). It is worth noting that cord hollowing and cell hollowing models are likely to be mechanistically very similar processes. Pinocytosis-derived vesicular compartments give rise to nascent fluid-filled lumenal spaces that-whether initially localized to extracellular spaces between endothelial cells or vacuolar compartments within endothelial cells-must ultimately be directed to the external spaces between endothelial cells and merge together to become the continuous vascular lumen.

\section{FORMATION OF CRANIAL AND RETINAL VASCULATURE}

Much of the discussion in this review so far has focused on the formation of the trunk vasculature, but the zebrafish has also begun to make contributions to our understanding of brain vessel development and disease. A thorough knowledge of the developmental biology of cranial vessel formation is important both for understanding development of the central nervous system and for understanding cerebrovascular pathologies such as stroke and cerebral hemorrhage.

\section{Lateral Dorsal Aortae and Cranial Vasculature}

Like the axial vessels in the trunk, the primary cranial vasculature, including the extracerebral vascular system, is established by vasculogenesis, or the assembly of new vessels from migration and coalescence of mesoderm-derived angioblasts (Lee et al. 2009). Following the establishment of the primary cranial vessels, a much more complex cranial vascular network develops via angiogenesis, or sprouting and growth of new vessels from preexisting vessels stabilized by the recruitment of mural cells. Examination of the cranial vascular anatomy of the developing zebrafish embryo reveals that zebrafish have an initial vascular plan that is well conserved in comparison to other developing vertebrates, including humans (Isogai et al. 2001).

The paired lateral dorsal aortae (LDA) are amongst the first vessels to assemble in the developing zebrafish, and are essential for providing the arterial supply for the entire head (Fig. 4) (Isogai et al. 2001). To form the LDA angioblasts from the anterior lateral plate mesoderm migrate medially as two anterior and posterior populations, coalescing into two sets of LDA primordia (Fig. 1C,E). Around $20 \mathrm{hpf}$ they join to form a single vessel on either side of the midline. The LDA then undergo angiogenesis in a caudal direction to fuse with the single posterior dorsal aorta, which as noted above also forms by vasculogenesis, assembling a Y-shaped junction between all of these large caliber arterial vessels (Isogai et al. 2001; Siekmann et al. 2009). At around the same time, the first bilateral primitive veins of the head, the primordial hindbrain channels (PHBC), are also assembling by vasculogenesis. The PHBC, emptying into the anterior carotid veins, initially provide the sole venous drainage for the head. The basilar artery (BA) is the first and most important artery to form in the hindbrain. It assembles along the ventral keel of the hindbrain, directly between two primitive bilateral veins, the primordial hindbrain channels (PHBCs). The BA is one of the most fundamental arteries in the vertebrate head, with many branches irrigating the cerebellum and brainstem. Irrigation of the neural tissues of the hindbrain is accomplished with the help of the slightly later-forming central arteries (CtAs), vessels that penetrate the hindbrain and interconnect the BA and PHBC. The first circulatory loop in the head is comprised of the heart, ventral aorta, LDA, primitive internal carotid artery, BA, PHBC, and PCV (Fig. 4). As development proceeds many additional angiogenic vessels come on line and the cranial vasculature becomes much more complex (Isogai et al. 2001).

Like the trunk vasculature, the formation of the cranial vasculature also depends on VEGF signaling. Inhibiting VEGF signaling leads to defects in formation of both the middle cerebral vessel, which runs along the mid-hindbrain 
A.V. Gore et al.
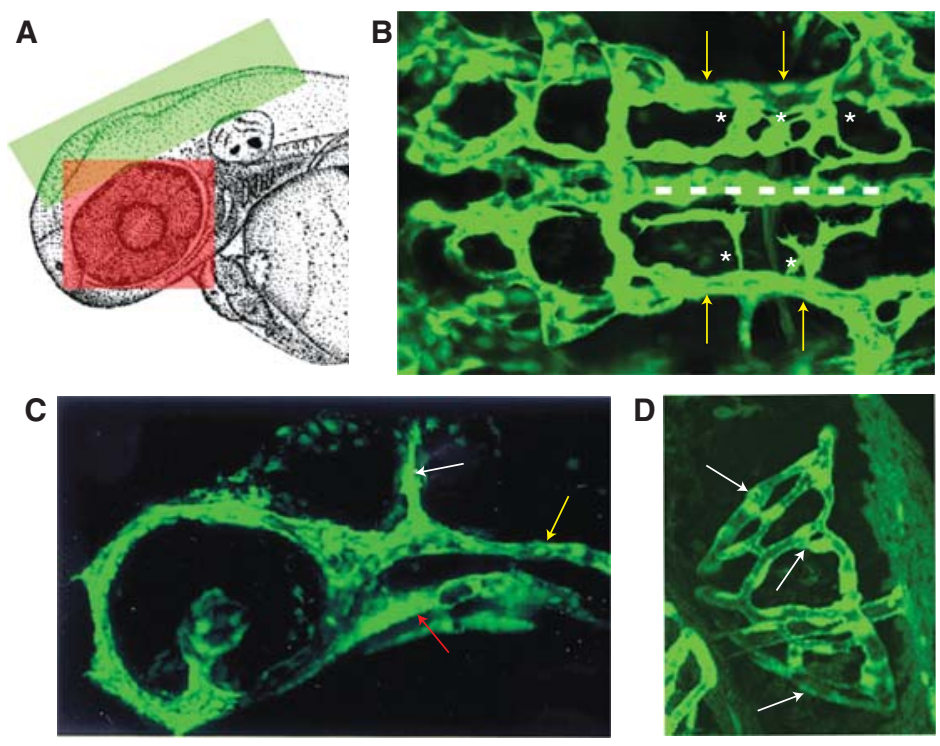

Figure 4. Early embryonic cranial and eye vasculature. (A) Schematic diagram of the head of a zebrafish embryo with the green and red boxed areas showing the approximate areas in the images in $B, C$, and $D$, respectively. $(B)$ Dorsal view of the cranial vasculature showing the primordial hindbrain channels (yellow arrows), basilar artery (dashed line), and central artery sprouts (asterisks). (C) Lateral view of the cranial vasculature showing the lateral dorsal aorta (red arrow), primordial hindbrain channel (yellow arrow), and mid cerebral vessel (white arrow). (D) Dorsal view of the optic vasculature of the right eye, showing the blood vessel network surrounding the lens (white arrows). Anterior is to the left in $B$ and $C$ and on top in $D$.

boundary, and the PHBC (Covassin et al. 2006). Proper cranial vessel formation also depends on additional, novel cues. Chemokine signaling involving the receptor cxcr4a and its ligand Sdf1/Cxcl12b has recently been shown to be important for LDA formation in the zebrafish (Siekmann et al. 2009). Chemokine signaling regulates diverse developmental processes, such as primordial germ cell migration, endoderm development, lateral line formation, and axon growth (Raz and Mahabaleshwar, 2009). Time-lapse video microscopy on cxcr4a mutant embryos shows that anterior endothelial cells fail to migrate and connect to form a complete LDA. Loss of CXCR4A function leads to incomplete LDA formation, but does not affect formation of the trunk vasculature. Even more recent studies have now shown that chemokine signaling is also required for the formation of the basilar artery, with $c x c r 4 a$-expressing BA progenitor cells aligned along the $c x c l 12 b$-expressing ventral neural keel (M Fujita and B Weinstein, unpubl.). These observations indicate an essential role for chemokine signaling in cranial vessel development but a dispensable role in the developing trunk blood vessels.

\section{Role of Endothelial Junctions in Vascular Permeability}

Endothelial cell-cell junctions play crucial roles in regulating vascular stability, structural integrity, and homeostasis. As in other vertebrates, vessels in the zebrafish show three different types of endothelial junctions; tight junctions, adherens junctions, and gap junctions. Tight and adherens junctions provide structural integrity to the developing trunk vasculature (Blum et al. 2008; Montero-Balaguer et al. 2009), whereas gap junctions are primarily used for endothelial cell-cell communication. At present, only a handful of markers are available to visualize endothelial cell-cell junctions and/or their components in zebrafish embryos. 
These include ZO-1, which localizes to tight junctions, VE-cadherin, which localizes to adherens junctions (Blum et al. 2008), and Connexin 43, which labels gap junctions (Desplantez et al. 2003; Dejana 2004). Very few studies have been performed to understand the molecular mechanisms regulating junction assembly in the zebrafish endothelium. Abnormal endothelial junctions are known to affect vascular integrity and can cause intracranial hemorrhages, making understanding mechanisms regulating junctional function of great clinical interest. Depletion of a small Ras related GTPase called rap1b in the zebrafish leads to both abnormal endothelial cell junctions and cranial hemorrhage (Gore et al. 2008). Mutation or depletion of rap $1 b$ interacting partners $\beta$-pix and pak2a also leads to cranial hemorrhage (Buchner et al. 2007; Liu et al. 2007). Combinations of small, functionally silent reductions in rap $1 b$ and its interacting partners $\beta$-pix, pak $2 a$, and krit1 together lead to cranial hemorrhage, demonstrating that these genes function together in regulating vascular integrity (Gore et al. 2008). A number of other studies have also identified additional signaling pathways contributing to the maintenance of vascular integrity. For example, in zebrafish analysis of Birc2 mutants, which have cranial hemorrhages, has shown that suppression of endothelial cell death pathways is important for endothelial integrity (Santoro et al. 2007).

\section{Formation of the Vasculature of the Zebrafish Eye}

The retinal vasculature is a capillary network of blood vessels that nourishes the inner retina. In humans, either excessive or deficient angiogenesis of these vessels frequently leads to loss of vision. The structure and function of the vertebrate eye is highly conserved. The zebrafish is an attractive model to study eye development, disease and regeneration because of its tractability as a genetic model system and usefulness for many advanced optical imaging techniques (Fadool and Dowling 2008). Recent studies have described the vascular anatomy of the zebrafish hyaloid-retinal vessels (Isogai et al.
2001; Alvarez et al. 2007). The optic artery (OA) branches from the primitive internal carotid artery (PICA) at 24-29 dpf, after initial vasculogenesis, and enters the eye ventrally through the optic fissure forming the hyaloid artery. Hyaloid artery then forms a single loop and exits the optic fissure as the hyaloid vein, continuing to the $\mathrm{PHBC}$ as the optic vein by $31 \mathrm{hpf}$. The portions of the optic vessels internal to the eye are called the hyaloid vessels, whereas the external portions are called the optic vessels (Isogai et al. 2001). The few endothelial cells between lens and retina give rise to the first hyaloid vessel, distinguishable by $60 \mathrm{hpf}$ as a rudimentary vasculature tightly attached to the lens. The vessels progressively branch, start to lose contact with the lens, and adhere to the inner limiting membrane of the juvenile retina by 30 days post fertilization. In mammals hyaloid vessel remodeling is governed by regression and neoangiogenesis, but this has not been observed in zebrafish (Alvarez et al. 2007).

As for the cranial vessels, the mechanism of hyaloid retinal vessel patterning has distinct and similar features compared to the trunk vessels. Mutations in the plexinD1 receptor gene out of bounds (obd) result in both patterning defects in trunk intersegmental vessels, and excessive primary branching of hyaloid vessels (Alvarez et al. 2007, 2009). However, other factors regulate vascular development in an eyespecific fashion. However, in zebrafish that lack lens development, the hyaloid retinal vasculature is disrupted, but vessel formation in the trunk in normal. These observations suggest that lens-derived signals are important for the development of the retinal but not the trunk vasculature (Alvarez et al. 2007). In mice, macrophages expressing $\mathrm{Wnt7b}$ promote regression of hyaloid vessels via programmed cell death in an eye-specific manner (Lobov et al. 2005). Small molecule screening in the zebrafish has also identified compounds with specific effects on the hyaloid and retinal vasculature (Alvarez et al. 2009; Kitambi et al. 2009). Additional studies should help to elucidate eye-specific molecular regulation of vascular development. 
A.V. Gore et al.

\section{LYMPHATIC DEVELOPMENT}

\section{Origin of Lymphatic Endothelial Cells}

In addition to their blood vascular system, most vertebrates possess a second, equally complex but separate vascular system, the lymphatic vascular system. The lymphatic system is essential for maintenance of interstitial fluid balance and immune responses. Recent work has also shown that lymphatics are the major pathway for tumor metastasis, making them critically important as potential targets for cancer therapies (reviewed in Tammela and Alitalo 2010). Despite its importance, lymphangiogenesis has been less explored compared to angiogenesis because of difficulties in identifying these vessels in vivo, limited lymphatic-specific markers, and a lack of effective model organisms in which lymphatic cells can be easily monitored and lymphatics genetically and/or experimentally manipulated. Over the past few years, molecular mechanisms controlling lymphangiogenesis have been begun to be revealed by identification of regulatory molecules and markers specific to the lymphatic endothelium. These molecular tools have, for example, permitted reexamination of the question of the embryonic origins of the first lymphatic endothelial cells (LECs), in particular whether they are derived from primitive venous endothelium or arise de novo from mesenchyme. Grafting studies in avian embryos (Wilting et al. 2000; Wilting et al. 2006) and analysis of a lymphatic marker, Prox1 (Wigle and Oliver 1999), in Xenopus tadpoles (Ny et al. 2005) suggest that lymphatics arise from both embryonic veins and mesenchyme. Genetic studies in mice, however, indicate a venous origin for the first LECs, showing the expression of Proxl in a subset of venous endothelial cells and migration of Prox1 positive cells from veins to form lymph sacs (Karkkainen et al. 2004). Tissue specific lineage labeling experiments further support the idea that venous endothelial cells are predominant source of LECs during murine development (Oliver 2004; Srinivasan et al. 2007).

The zebrafish possesses a bona fide lymphatic vascular system that shares important morphological, molecular (for example, VEGFC and Prox 1 expression) and functional characteristics (e.g., drainage and collection of subcutaneously injected dye) with lymphatic vessels of higher vertebrates (Fig. 5) (Kuchler et al. 2006; Yaniv et al. 2006). One important aspect of zebrafish as a model organism for studying lymphangiogenesis is the ability to easily observe and track lymphatic endothelial cells within living embryos and larvae due their optical clarity and the availability of vascular specific transgenic lines expressing GFP in blood and lymphatic endothelial cells (Lawson and Weinstein 2002b). This permits examination of LEC development at the singlecell level via high-resolution optical imaging in living embryos and larvae (Weinstein 2002; Kamei et al. 2004; Cha and Weinstein 2007). Direct lineage tracing experiments using longterm time-lapse imaging have shown that LECs destined to form the lymphatic thoracic duct originate in the posterior cardinal vein, although they undergo a long and circuitous migration before reaching their final destination (Yaniv et al. 2006). These results provided the most conclusive evidence to date supporting the idea that the earliest progenitors for lymphatic endothelial cells are vein-derived, although they do not preclude the possibility of a later contribution to lymphatic progenitors from mesenchyme in the zebrafish.

\section{Formation of the Lymphatic System}

The lymphatic system, composed of blindended capillaries and large collecting lymphatic vessels, is an independent vascular network separated from the blood vascular system except at specific connection points between large collecting lymphatic vessels and veins (Jeltsch et al. 2003). The lymphatic vessels start to develop after the establishment of a functional cardiovascular system, and the lymphatic system is present in almost all vascularized tissues, except the central nervous system and bone marrow. Interestingly, the trajectory of the collecting lymphatic vessels is highly associated with the route of blood vessels such as arteries. 
Vascular Development in the Zebrafish
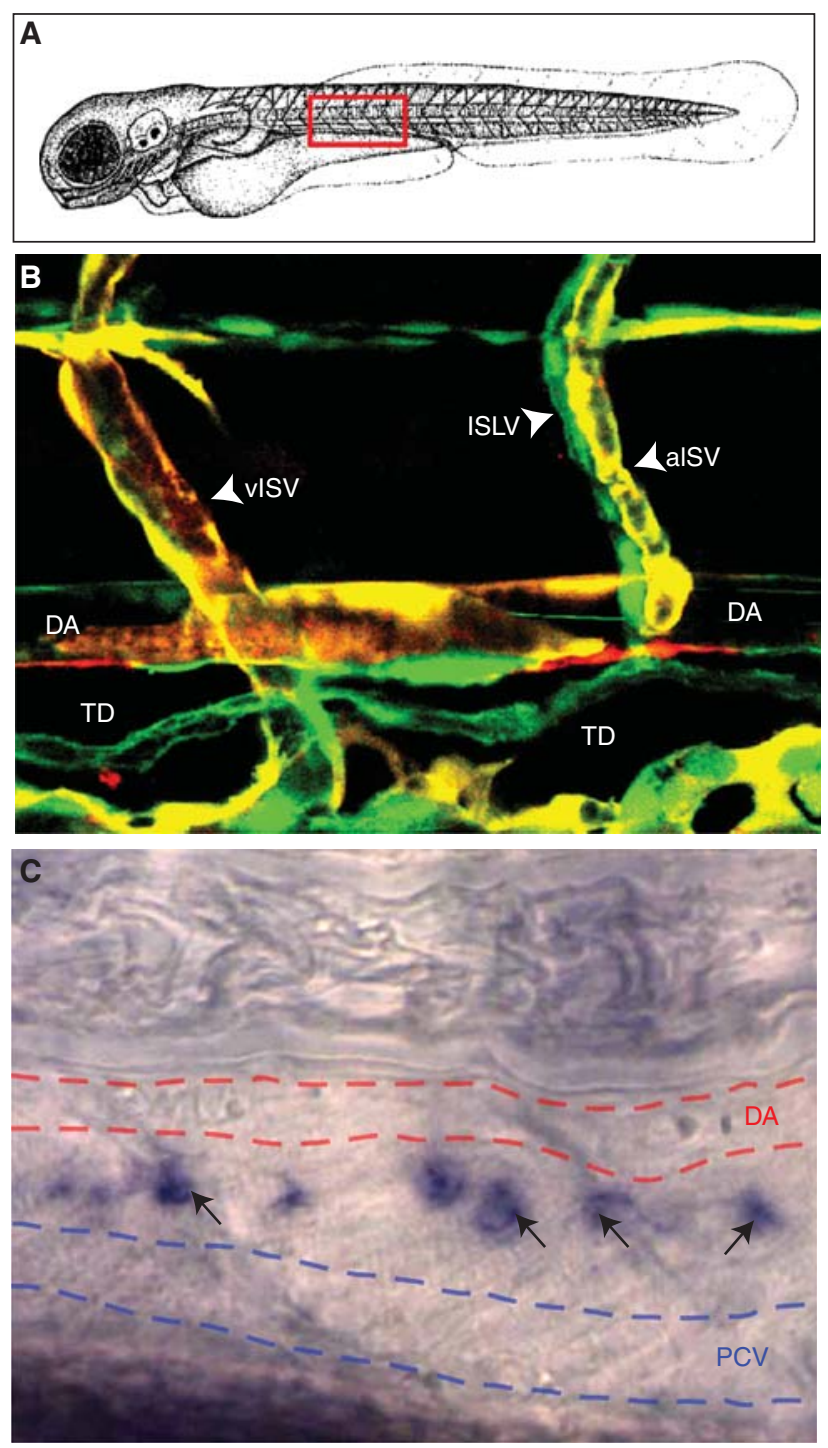

Figure 5. Lymphatic vasculature in zebrafish. (A) Schematic diagram of a zebrafish embryo with a red box highlighting the approximate region shown in $B$ and $C$. (B) Confocal image of blood vessels (red/ yellow) and lymphatic vessels (green) in a 3 dpf $T g$ (flk:mCherry), Tg(flila:EGFP) $)^{y 1}$ double transgenic animal. Note coalignment of intersegmental lymphatic vessels (ISLV) with arterial intersegmental vessels (aISV) but not with venous intersegmental vessels (vISV). (C) Transmitted light image of a $4 \mathrm{dpf}$ zebrafish larva subjected to whole-mount in situ hybridization, probing for prox1. Expression of prox 1 (black arrows) is detected in the thoracic duct (TD), a major evolutionarily conserved lymphatic vessel located between the dorsal aorta (DA, red dashed lines) and posterior cardinal vein (PCV, blue dashed lines).
Recent studies in mice provide insight into how the primitive lymphatic vasculature is formed during embryogenesis. Initially, Sox 18 is expressed in a LYVE1-positive subpopulation of venous endothelial cells located in the cardinal vein. The biased expression of Sox 18 is thought to induce polarized expression of Proxl in the same cells, resulting in LEC specification of the venous endothelial cells (Francois et al. 2008). The Proxl-positive LECs, then begin to bud from the primitive veins and migrate in a polarized manner (Wigle and
Oliver 1999; Oliver 2004). These processes are accomplished by signaling between VEGFR3 in the Prox1-positive LEC progenitors and its ligand VEGFC arising from the lateral mesenchyme (Makinen et al. 2001; Karkkainen et al. 2004; Tammela et al. 2005; Karpanen and Alitalo 2008). VEGFC induces the proliferation and budding of the Prox1-positive LEC progenitors in the vein and promotes migration of these progenitors toward VEGFC-producing sources, giving rise to the formation of lymph sacs in the lateral to the central veins. The 
A.V. Gore et al.

lymphatics then extend throughout the embryo by budding and sprouting of LECs from the lymph sac. Finally, the spreading lymphatics undergo remodeling and maturation by terminal differentiation, leading to the formation of the complete lymphatic network (Oliver 2004; Tammela and Alitalo 2010).

The basic mechanism controlling the initial formation of lymphatic vasculature in zebrafish embryos is highly similar to that in murine embryos. As in the mouse, jugular lymphatic sacs initiate rostral lymphatic network development in the fish. In the trunk, the key event of initial lymphangiogenesis is the formation of the parachordal vessels ( $\mathrm{PAV}$, also termed parachordal line) from secondary sprouts emerging from the posterior cardinal vein (PCV) (Isogai et al. 2003). As in mouse embryos, Proxl is important for lymphatic specification from a subpopulation of zebrafish PCV endothelial cells, because the thoracic duct fails to form in Prox1-deficient embryos (Yaniv et al. 2006). VEGFC-VEGFR3 signaling is also likely to induce budding and migration of the Prox1postive secondary sprouting cells in zebrafish. Knockdown of VEGFC or overexpression of dominant-negative VEGFR3 causes loss of secondary sprouts, PAV formation, and thoracic duct formation (Kuchler et al. 2006; Yaniv et al. 2006; Hogan et al. 2009). A recent study using forward genetic screening identified a matrix-associated protein, Collagen and calcium binding EGF domain 1 (CCBE1), that appears to also be involved in a non-cell-autonomous manner in budding and migration of the secondary sprouts (Hogan et al. 2009). Mutations in human ccbel are associated with Hennekam syndrome (generalized lymphatic dysplasia, MIN 235510) characterized by intestinal lymphangiectasia with severe peripheral lymphedema with mental retardation, implying functional conservation of CCBE1 for lymphatic development from zebrafish to human (Connell et al. 2010; Alders et al. 2009) and verifying the relevance of the zebrafish as a clinically relevant animal model for studying the lymphatics. It is still unclear whether CCBE1 is linked to VEGFC signaling and how it functions during lymphatic budding and migration.
After the parachordal has formed lymphatic progenitors migrate dorsally and ventrally along arterial intersegmental vessels to begin formation of the rest of the trunk lymphatic network (Yaniv et al. 2006; Bussmann et al. 2010). These processes are highly stereotyped- lymphatic progenitors always migrate along arterial intersegmental vessels but not venous intersegmental vessels, showing that arterial blood vessels act as specific guidance templates for migration of LECs (Yaniv et al. 2006; Bussmann et al. 2010). The ventrally-migrating LECs branch rostally and caudally between the dorsal aorta and PCV to form the thoracic duct via proliferation of migrating LECs (Yaniv et al. 2006). The dorsally-migrating LEC branch rostrally and caudally just below the DLAV to form the dorsal lymphatic line. In this way, the simple initial primary lymphatic network of the trunk is formed-a primary network highly similar to that found in other developing vertebrates. With further development, however, a more complicated lymphatic network is established by further lymphangiogenic growth from this primary network.

Together, recent studies have emphasized that zebrafish is a valuable model organism to study developmental lymphangiogenesis and lymphatic network formation. The accessibility of this model to high-throughput forwardgenetics and the optical clarity of its embryos and larvae for high-resolution imaging make it useful for uncovering novel mechanisms regulating lymphatic development.

\section{CONCLUDING REMARKS}

The elaborate and precise patterning of the vertebrate vascular system requires a complex network of gene signaling pathways, and insight into this network has great clinical relevance toward the understanding of a variety of human diseases. Despite being a well-established vertebrate model system for studying embryonic development, and its rising importance in vascular research, zebrafish as a model system has not yet been maximally used to study the development of the vascular system. Recent studies have shown convincingly that important 
Vascular Development in the Zebrafish

mechanisms of vascular development are conserved between the zebrafish and higher vertebrates, confirming that a great deal can be learned about vascular development in mammals by exploiting the advantages offered by the zebrafish. In recent years, development of new techniques to manipulate zebrafish genome, image at high resolution, and perform large-scale drug screens have further increased the potential of this system to study vascular development. The identification of a lymphatic vascular system in this organism also highlights the importance and availability of zebrafish as a model to study key steps in lymphatic development. It seems likely that many new important discoveries in blood and lymphatic vascular biology will be made in the coming years using the zebrafish.

\section{ACKNOWLEDGMENTS}

We thank members of the Weinstein lab for comments, advice, and suggestions. This work was supported by the intramural program of the NICHD, NIH, and by the Leducq Foundation.

\section{REFERENCES}

Alders M, Hogan BM, Gjini E, Salehi F, Al-Gazali L, Hennekam EA, Holmberg EE, Mannens MM, Mulder MF, Offerhaus GJ, et al. 2009. Mutations in CCBE1 cause generalized lymph vessel dysplasia in humans. Nat Genet 41: 1272-1274.

Alvarez Y, Cederlund ML, Cottell DC, Bill BR, Ekker SC, Torres-Vazquez J, Weinstein BM, Hyde DR, Vihtelic TS, Kennedy BN. 2007. Genetic determinants of hyaloid and retinal vasculature in zebrafish. BMC Dev Biol 7: 114.

Alvarez Y, Astudillo O, Jensen L, Reynolds AL, Waghorne N, Brazil DP, Cao Y, O’Connor JJ, Kennedy BN. 2009. Selective inhibition of retinal angiogenesis by targeting PI3 kinase. PLoS One 4: e7867.

Bayless KJ, Davis GE. 2002. The Cdc42 and Rac1 GTPases are required for capillary lumen formation in threedimensional extracellular matrices. J Cell Sci 115: 1123-1136.

Bayless KJ, Salazar R, Davis GE. 2000. RGD-dependent vacuolation and lumen formation observed during endothelial cell morphogenesis in three-dimensional fibrin matrices involves the $\alpha_{\mathrm{v}} \beta_{3}$ and $\alpha_{5} \beta_{1}$ integrins. Am J Pathol 156: 1673-1683.

Blum Y, Belting HG, Ellertsdottir E, Herwig L, Luders F, Affolter M. 2008. Complex cell rearrangements during intersegmental vessel sprouting and vessel fusion in the zebrafish embryo. Dev Biol 316: 312-322.
Bouvree K, Larrivee B, Lv X, Yuan L, DeLafarge B, Freitas C, Mathivet T, Breant C, Tessier-Lavigne M, Bikfalvi A, et al. 2008. Netrin-1 inhibits sprouting angiogenesis in developing avian embryos. Dev Biol 318: 172-183.

Bressan M, Davis P, Timmer J, Herzlinger D, Mikawa T. 2009. Notochord-derived BMP antagonists inhibit endothelial cell generation and network formation. Dev Biol 326: $101-111$.

Buchner DA, Su F, Yamaoka JS, Kamei M, Shavit JA, Barthel LK, McGee B, Amigo JD, Kim S, Hanosh AW, et al. 2007. pak2a mutations cause cerebral hemorrhage in redhead zebrafish. Proc Natl Acad Sci 104: 13996-4001.

Bussmann J, Bos FL, Urasaki A, Kawakami K, Duckers HJ, Schulte-Merker S. 2010. Arteries provide essential guidance cues for lymphatic endothelial cells in the zebrafish trunk. Development 137: 2653-2657.

Cermenati S, Moleri S, Cimbro S, Corti P, Del Giacco L, Amodeo R, Dejana E, Koopman P, Cotelli F, Beltrame M. 2008. Sox18 and Sox7 play redundant roles in vascular development. Blood 111: 2657-2666.

Cha YR, Weinstein BM. 2007. Visualization and experimental analysis of blood vessel formation using transgenic zebrafish. Birth Defects Res C Embryo Today 81: 286-296.

Chappell JC, Taylor SM, Ferrara N, Bautch VL. 2009. Local guidance of emerging vessel sprouts requires soluble Flt-1. Dev Cell 17: 377-386.

Chen Z, Fisher RJ, Riggs CW, Rhim JS, Lautenberger JA. 1997. Inhibition of vascular endothelial growth factorinduced endothelial cell migration by ETS1 antisense oligonucleotides. Cancer Res 57: 2013-2019.

Childs S, Chen JN, Garrity DM, Fishman MC. 2002. Patterning of angiogenesis in the zebrafish embryo. Development 129: 973-982.

Cleaver O, Krieg PA. 1998. VEGF mediates angioblast migration during development of the dorsal aorta in Xenopus. Development 125: 3905-3914.

Cleaver O, Seufert DW, Krieg PA. 2000. Endoderm patterning by the notochord: Development of the hypochord in Xenopus. Development 127: 869-879.

Connell F, Kalidas K, Ostergaard P, Brice G, Homfray T, Roberts L, Bunyan DJ, Mitton S, Mansour S, Mortimer P, et al. 2010. Linkage and sequence analysis indicate that CCBE1 is mutated in recessively inherited generalised lymphatic dysplasia. Hum Genet 127: 231-241.

Covassin LD, Villefranc JA, Kacergis MC, Weinstein BM, Lawson ND. 2006. Distinct genetic interactions between multiple Vegf receptors are required for development of different blood vessel types in zebrafish. Proc Natl Acad Sci 103: 6554-6559.

Davis GE, Camarillo CW. 1996. An $\alpha 2 \beta 1$ integrindependent pinocytic mechanism involving intracellular vacuole formation and coalescence regulates capillary lumen and tube formation in three-dimensional collagen matrix. Exp Cell Res 224: 39-51.

Dejana E. 2004. Endothelial cell-cell junctions: Happy together. Nat Rev Mol Cell Biol 5: 261-270.

Desplantez T, Marics I, Jarry-Guichard T, Veteikis R, Briand JP, Weingart R, Gros D. 2003. Characterization of zebrafish Cx43.4 connexin and its channels. Exp Physiol 88: $681-690$. 
A.V. Gore et al.

Detrich HW 3rd, Kieran MW, Chan FY, Barone LM, Yee K, Rundstadler JA, Pratt S, Ransom D, Zon LI. 1995. Intraembryonic hematopoietic cell migration during vertebrate development. Proc Natl Acad Sci 92: 10713-10717.

De Val S, Chi NC, Meadows SM, Minovitsky S, Anderson JP, Harris IS, Ehlers ML, Agarwal P, Visel A, Xu SM, et al. 2008. Combinatorial regulation of endothelial gene expression by ets and forkhead transcription factors. Cell 135: 1053-1064.

Drake CJ, Fleming PA. 2000. Vasculogenesis in the day 6.5 to 9.5 mouse embryo. Blood 95: 1671-1679.

Fadool JM, Dowling JE. 2008. Zebrafish: A model system for the study of eye genetics. Prog Retin Eye Res 27: 89-110.

Folkman J, Haudenschild C. 1980. Angiogenesis in vitro. Nature 288: 551-556.

Fouquet B, Weinstein BM, Serluca FC, Fishman MC. 1997. Vessel patterning in the embryo of the zebrafish: Guidance by notochord. Dev Biol 183: 37-48.

Francois M, Caprini A, Hosking B, Orsenigo F, Wilhelm D, Browne C, Paavonen K, Karnezis T, Shayan R, Downes M, et al. 2008. Sox18 induces development of the lymphatic vasculature in mice. Nature 456: 643-647.

Gerety SS, Anderson DJ. 2002. Cardiovascular ephrinB2 function is essential for embryonic angiogenesis. Development 129: 1397-1410.

Gerhardt H, Golding M, Fruttiger M, Ruhrberg C, Lundkvist A, Abramsson A, Jeltsch M, Mitchell C, Alitalo K, Shima D, et al. 2003. VEGF guides angiogenic sprouting utilizing endothelial tip cell filopodia. J Cell Biol 161: 1163-1177.

Gitler AD, Lu MM, Epstein JA. 2004. PlexinD1 and semaphorin signaling are required in endothelial cells for cardiovascular development. Dev Cell 7: 107-116.

Gore AV, Lampugnani MG, Dye L, Dejana E, Weinstein BM. 2008. Combinatorial interaction between CCM pathway genes precipitates hemorrhagic stroke. Dis Model Mech 1: 275-281.

Gu C, Yoshida Y, Livet J, Reimert DV, Mann F, Merte J, Henderson CE, Jessell TM, Kolodkin AL, Ginty DD. 2005 Semaphorin 3E and plexin-D1 control vascular pattern independently of neuropilins. Science 307: 265-268.

Haar JL, Ackerman GA. 1971. Ultrastructural changes in mouse yolk sac associated with the initiation of vitelline circulation. Anat Rec 170: 437-455.

Habeck H, Odenthal J, Walderich B, Maischein H, SchulteMerker S. 2002. Analysis of a zebrafish VEGF receptor mutant reveals specific disruption of angiogenesis. Curr Biol 12: 1405-1412.

Hellstrom M, Phng LK, Hofmann JJ, Wallgard E, Coultas L, Lindblom P, Alva J, Nilsson AK, Karlsson L, Gaiano N, et al. 2007. Dll4 signalling through Notch1 regulates formation of tip cells during angiogenesis. Nature 445: 776-780.

Herbert SP, Huisken J, Kim TN, Feldman ME, Houseman BT, Wang RA, Shokat KM, Stainier DY. 2009. Arterialvenous segregation by selective cell sprouting: An alternative mode of blood vessel formation. Science 326: $294-298$.

Herpers R, van de Kamp E, Duckers HJ, Schulte-Merker S. 2008. Redundant roles for sox7 and sox 18 in arteriovenous specification in zebrafish. Circ Res 102: 12-15.
Hogan BM, Bos FL, Bussmann J, Witte M, Chi NC, Duckers HJ, Schulte-Merker S. 2009. Ccbel is required for embryonic lymphangiogenesis and venous sprouting. Nat Genet 41: 396-398.

Hong CC, Peterson QP, Hong JY, Peterson RT. 2006. Artery/ vein specification is governed by opposing phosphatidylinositol-3 kinase and MAP kinase/ERK signaling. Curr Biol 16: 1366-1372.

Huber TL, Kouskoff V, Fehling HJ, Palis J, Keller G. 2004. Haemangioblast commitment is initiated in the primitive streak of the mouse embryo. Nature 432: 625-630.

Isogai S, Horiguchi M, Weinstein BM. 2001. The vascular anatomy of the developing zebrafish: An atlas of embryonic and early larval development. Dev Biol 230: $278-301$.

Isogai S, Lawson ND, Torrealday S, Horiguchi M, Weinstein BM. 2003. Angiogenic network formation in the developing vertebrate trunk. Development 130: 5281-5290.

Isogai S, Hitomi J, Yaniv K, Weinstein BM. 2009. Zebrafish as a new animal model to study lymphangiogenesis. Anat Sci Int 84: 102-111.

Jeltsch M, Tammela T, Alitalo K, Wilting J. 2003. Genesis and pathogenesis of lymphatic vessels. Cell Tissue Res 314: 69-84.

Jin SW, Beis D, Mitchell T, Chen JN, Stainier DY. 2005. Cellular and molecular analyses of vascular tube and lumen formation in zebrafish. Development 132: 5199-5209.

Kabrun N, Buhring HJ, Choi K, Ullrich A, Risau W, Keller G. 1997. Flk-1 expression defines a population of early embryonic hematopoietic precursors. Development 124: 2039-2048.

Kamei M, Isogai S, Weinstein BM. 2004. Imaging blood vessels in the zebrafish. Methods Cell Biol 76: 51-74.

Kamei M, Saunders WB, Bayless KJ, Dye L, Davis GE, Weinstein BM. 2006. Endothelial tubes assemble from intracellular vacuoles in vivo. Nature 442: 453-456.

Karkkainen MJ, Haiko P, Sainio K, Partanen J, Taipale J, Petrova TV, Jeltsch M, Jackson DG, Talikka M, Rauvala H, et al. 2004. Vascular endothelial growth factor C is required for sprouting of the first lymphatic vessels from embryonic veins. Nat Immunol 5: 74-80.

Karpanen T, Alitalo K. 2008. Molecular biology and pathology of lymphangiogenesis. Annu Rev Pathol 3: 367-397.

Kimmel CB, Warga RM, Schilling TF. 1990. Origin and organization of the zebrafish fate map. Development 108: $581-594$.

Kitambi SS, McCulloch KJ, Peterson RT, Malicki JJ. 2009. Small molecule screen for compounds that affect vascular development in the zebrafish retina. Mech Dev 126: 464477.

Koh W, Mahan RD, Davis GE. 2008. Cdc42- and Rac1mediated endothelial lumen formation requires Pak2, Pak4 and Par3, and PKC-dependent signaling. J Cell Sci 121: 989-1001.

Koh W, Sachidanandam K, Stratman AN, Sacharidou A, Mayo AM, Murphy EA, Cheresh DA, Davis GE. 2009. Formation of endothelial lumens requires a coordinated PKCepsilon-, Src-, Pak- and Raf-kinase-dependent signaling cascade downstream of Cdc42 activation. J Cell Sci 122: $1812-1822$. 
Kuchler AM, Gjini E, Peterson-Maduro J, Cancilla B, Wolburg H, Schulte-Merker S. 2006. Development of the zebrafish lymphatic system requires VEGFC signaling. Curr Biol 16: 1244-1248.

Lamont RE, Lamont EJ, Childs SJ. 2009. Antagonistic interactions among Plexins regulate the timing of intersegmental vessel formation. Dev Biol 331: 199-209.

Larrivee B, Freitas C, Trombe M, Lv X, Delafarge B, Yuan L, Bouvree K, Breant C, Del Toro R, Brechot N, et al. 2007. Activation of the UNC5B receptor by Netrin-1 inhibits sprouting angiogenesis. Genes Dev 21: 2433-2447.

Lawson ND, Weinstein BM. 2002a. Arteries and veins: Making a difference with zebrafish. Nat Rev Genet 3: 674-682.

Lawson ND, Weinstein BM. 2002b. In vivo imaging of embryonic vascular development using transgenic zebrafish. Dev Biol 248: 307-318

Lawson ND, Scheer N, Pham VN, Kim CH, Chitnis AB, Campos-Ortega JA, Weinstein BM. 2001. Notch signaling is required for arterial-venous differentiation during embryonic vascular development. Development 128: 3675-3683.

Lawson ND, Vogel AM, Weinstein BM. 2002. Sonic hedgehog and vascular endothelial growth factor act upstream of the Notch pathway during arterial endothelial differentiation. Dev Cell 3: 127-136.

Lawson ND, Mugford JW, Diamond BA, Weinstein BM. 2003. PPPhospholipase $C \gamma-1$ is required downstream of vascular endothelial growth factor during arterial development. Genes Dev 17: 1346-1351.

Lee HS, Han J, Bai HJ, Kim KW. 2009. Brain angiogenesis in developmental and pathological processes: Regulation, molecular and cellular communication at the neurovascular interface. FEBS J 276: 4622-4635.

Lelievre E, Lionneton F, Soncin F, Vandenbunder B. 2001 The Ets family contains transcriptional activators and repressors involved in angiogenesis. Int J Biochem Cell Biol 33: 391-407.

Lelievre E, Mattot V, Huber P, Vandenbunder B, Soncin F 2000. ETS1 lowers capillary endothelial cell density at confluence and induces the expression of VE-cadherin. Oncogene 19: 2438-2446.

le Noble F, Klein C, Tintu A, Pries A, Buschmann I. 2008 Neural guidance molecules, tip cells, and mechanical factors in vascular development. Cardiovasc Res 78: $232-241$.

Leslie JD, Ariza-McNaughton L, Bermange AL, McAdow R, Johnson SL, Lewis J. 2007. Endothelial signalling by the Notch ligand Delta-like 4 restricts angiogenesis. Development 134: 839-844.

Liu J, Fraser SD, Faloon PW, Rollins EL, Vom Berg J, Starovic-Subota O, Laliberte AL, Chen JN, Serluca FC, Childs SJ. 2007. A $\beta$ Pix Pak2a signaling pathway regulates cerebral vascular stability in zebrafish. Proc Natl Acad Sci 104: 13990-13995.

Lobov IB, Rao S, Carroll TJ, Vallance JE, Ito M, Ondr JK, Kurup S, Glass DA, Patel MS, Shu W, et al. 2005. WNT7b mediates macrophage-induced programmed cell death in patterning of the vasculature. Nature 437: 417-421.

Lu X, Le Noble F, Yuan L, Jiang Q, De Lafarge B, Sugiyama D, Breant C, Claes F, De Smet F, Thomas JL, et al. 2004. The netrin receptor UNC5B mediates guidance events controlling morphogenesis of the vascular system. Nature 432: $179-186$.

Lubarsky B, Krasnow MA. 2003. Tube morphogenesis: Making and shaping biological tubes. Cell 112: 19-28.

Makinen T, Jussila L, Veikkola T, Karpanen T, Kettunen MI, Pulkkanen KJ, Kauppinen R, Jackson DG, Kubo H, Nishikawa S, et al. 2001. Inhibition of lymphangiogenesis with resulting lymphedema in transgenic mice expressing soluble VEGF receptor-3. Nat Med 7: 199-205.

McKinney MC, Weinstein BM. 2008. Using the zebrafish to study vessel formation. Methods Enzymol 444: 65-97.

Meadows SM, Salanga MC, Krieg PA. 2009. Krüppel-like factor 2 cooperates with the ETS family protein ERG to activate Flk1 expression during vascular development. Development 136: 1115-1125.

Melani M, Weinstein BM. 2010. Common factors regulating patterning of the nervous and vascular systems. Annu Rev Cell Dev Biol 10: 639-665.

Montero-Balaguer M, Swirsding K, Orsenigo F, Cotelli F Mione M, Dejana E. 2009. Stable vascular connections and remodeling require full expression of VE-cadherin in zebrafish embryos. PLoS One 4: e5772.

Moore MA, Owen JJ. 1965. Chromosome marker studies on the development of the haemopoietic system in the chick embryo. Nature 208: 956 passim.

Moyon D, Pardanaud L, Yuan L, Breant C, Eichmann A. 2001. Plasticity of endothelial cells during arterial-venous differentiation in the avian embryo. Development 128: 3359-3370.

Mukouyama YS, Shin D, Britsch S, Taniguchi M, Anderson DJ. 2002. Sensory nerves determine the pattern of arterial differentiation and blood vessel branching in the skin. Cell 109: 693-705.

Murray PDF. 1932. The development in vitro of the blood of the early chick embryo. Proc Roy Soc London B 111: 497-521.

Nakano T, Abe M, Tanaka K, Shineha R, Satomi S, Sato Y. 2000. Angiogenesis inhibition by transdominant mutant Ets-1. J Cell Physiol 184: 255-262.

Navankasattusas S, Whitehead KJ, Suli A, Sorensen LK, Lim AH, Zhao J, Park KW, Wythe JD, Thomas KR, Chien CB, et al. 2008. The netrin receptor UNC5B promotes angiogenesis in specific vascular beds. Development 135: 659-667.

Ny A, Koch M, Schneider M, Neven E, Tong RT, Maity S, Fischer C, Plaisance S, Lambrechts D, Heligon C, et al. 2005. A genetic Xenopus laevis tadpole model to study lymphangiogenesis. Nat Med 11: 998-1004.

Oliver G. 2004. Lymphatic vasculature development. Nat Rev Immunol 4: 35-45.

Othman-Hassan K, Patel K, Papoutsi M, RodriguezNiedenfuhr M, Christ B, Wilting J. 2001. Arterial identity of endothelial cells is controlled by local cues. Dev Biol 237: 398-409.

Paik EJ, Zon LI. 2010. Hematopoietic development in the zebrafish. Int J Dev Biol 54: 1127-1137.

Parker LH, Schmidt M, Jin SW, Gray AM, Beis D, Pham T, Frantz G, Palmieri S, Hillan K, Stainier DY, et al. 2004. The endothelial-cell-derived secreted factor Egfl7 regulates vascular tube formation. Nature 428: 754-758. 
A.V. Gore et al.

Pendeville H, Winandy M, Manfroid I, Nivelles O, Motte P, Pasque V, Peers B, Struman I, Martial JA, Voz ML. 2008. Zebrafish Sox7 and Sox18 function together to control arterial-venous identity. Dev Biol 317: 405-416.

Pham VN, Lawson ND, Mugford JW, Dye L, Castranova D, Lo B, Weinstein BM. 2007. Combinatorial function of ETS transcription factors in the developing vasculature. Dev Biol 303: 772-783.

Pola R, Ling LE, Silver M, Corbley MJ, Kearney M, Blake Pepinsky R, Shapiro R, Taylor FR, Baker DP, Asahara T, et al. 2001. The morphogen Sonic hedgehog is an indirect angiogenic agent upregulating two families of angiogenic growth factors. Nat Med 7: 706-711.

Raz E, Mahabaleshwar H. 2009. Chemokine signaling in embryonic cell migration: A fisheye view. Development 136: $1223-1229$.

Rodriguez F, Vacaru A, Overvoorde J, den Hertog J. 2008. The receptor protein-tyrosine phosphatase, Dep1, acts in arterial/venous cell fate decisions in zebrafish development. Dev Biol 324: 122-130.

Roman BL, Pham VN, Lawson ND, Kulik M, Childs S, Lekven AC, Garrity DM, Moon RT, Fishman MC, Lechleider RJ, et al. 2002. Disruption of acvrl1 increases endothelial cell number in zebrafish cranial vessels. Development 129: 3009-3019.

Sabin FR. 1920. Studies on the origin of blood-vessels and of red blood-corpuscles as seen in the living blastoderm of chicks during the second day of incubation. Contrib Embryol 9: 213-262.

Salanga MC, Meadows SM, Myers CT, Krieg PA. 2010. ETS family protein ETV2 is required for initiation of the endothelial lineage but not the hematopoietic lineage in the Xenopus embryo. Dev Dyn 239: 1178-1187.

Santoro MM, Samuel T, Mitchell T, Reed JC, Stainier DY. 2007. Birc2 (cIap1) regulates endothelial cell integrity and blood vessel homeostasis. Nat Genet 39: 1397-1402.

Siekmann AF, Lawson ND. 2007. Notch signalling limits angiogenic cell behaviour in developing zebrafish arteries. Nature 445: 781-784.

Siekmann AF, Standley C, Fogarty KE, Wolfe SA, Lawson ND. 2009. Chemokine signaling guides regional patterning of the first embryonic artery. Genes Dev 23: 2272 2277.

Srinivasan RS, Dillard ME, Lagutin OV, Lin FJ, Tsai S, Tsai MJ, Samokhvalov IM, Oliver G. 2007. Lineage tracing demonstrates the venous origin of the mammalian lymphatic vasculature. Genes Dev 21: 2422-2432.

Stainier DY, Weinstein BM, Detrich HW 3rd, Zon LI, Fishman MC. 1995. Cloche, an early acting zebrafish gene, is required by both the endothelial and hematopoietic lineages. Development 121: 3141-3150.

Strilic B, Kucera T, Eglinger J, Hughes MR, McNagny KM, Tsukita S, Dejana E, Ferrara N, Lammert E. 2009. The molecular basis of vascular lumen formation in the developing mouse aorta. Dev Cell 17: 505-515.

Suchting S, Freitas C, le Noble F, Benedito R, Breant C, Duarte A, Eichmann A. 2007. The Notch ligand Delta-like 4 negatively regulates endothelial tip cell formation and vessel branching. Proc Natl Acad Sci 104: $3225-3230$.
Sumanas S, Gomez G, Zhao Y, Park C, Choi K, Lin S. 2008. Interplay among Etsrp/ER71, Scl, and Alk8 signaling controls endothelial and myeloid cell formation. Blood 111: $4500-4510$

Sumanas S, Lin S. 2006. Ets1-related protein is a key regulator of vasculogenesis in zebrafish. PLoS Biol 4: e10.

Sumoy L, Keasey JB, Dittman TD, Kimelman D. 1997. A role for notochord in axial vascular development revealed by analysis of phenotype and the expression of VEGR-2 in zebrafish flh and ntl mutant embryos. Mech Dev 63: $15-27$.

Swift MR, Weinstein BM. 2009. Arterial-venous specification during development. Circ Res 104: 576-588.

Tammela T, Alitalo K. 2010. Lymphangiogenesis: Molecular mechanisms and future promise. Cell 140: 460-476.

Tammela T, Enholm B, Alitalo K, Paavonen K. 2005. The biology of vascular endothelial growth factors. Cardiovasc Res 65: 550-563.

Tammela T, Zarkada G, Wallgard E, Murtomaki A, Suchting S, Wirzenius M, Waltari M, Hellstrom M, Schomber T, Peltonen R, et al. 2008. Blocking VEGFR-3 suppresses angiogenic sprouting and vascular network formation. Nature 454: 656-660.

Thompson MA, Ransom DG, Pratt SJ, MacLennan $\mathrm{H}$, Kieran MW, Detrich HW 3rd, Vail B. Huber TL, Paw B, Brownlie AJ, et al. 1998. The cloche and spadetail genes differentially affect hematopoiesis and vasculogenesis. Dev Biol 197: 248-269.

Torres-Vazquez J, Gitler AD, Fraser SD, Berk JD, Van NP, Fishman MC, Childs S, Epstein JA, Weinstein BM. 2004. Semaphorin-plexin signaling guides patterning of the developing vasculature. Dev Cell 7: 117-123.

Visconti RP, Richardson CD, Sato TN. 2002. Orchestration of angiogenesis and arteriovenous contribution by angiopoietins and vascular endothelial growth factor (VEGF). Proc Natl Acad Sci 99: 8219-8224.

Vogeli KM, Jin SW, Martin GR, Stainier DY. 2006. A common progenitor for haematopoietic and endothelial lineages in the zebrafish gastrula. Nature 443: 337-339.

Vokes SA, Krieg PA. 2002. Endoderm is required for vascular endothelial tube formation, but not for angioblast specification. Development 129: 775-785.

Vokes SA, Yatskievych TA, Heimark RL, McMahon J, McMahon AP, Antin PB, Krieg PA. 2004. Hedgehog signaling is essential for endothelial tube formation during vasculogenesis. Development 131: 4371-4380.

Wakiya K, Begue A, Stehelin D, Shibuya M. 1996. A cAMP response element and an Ets motif are involved in the transcriptional regulation of flt-1 tyrosine kinase (vascular endothelial growth factor receptor 1) gene. J Biol Chem 271: 30823-30828.

Wang Y, Nakayama M, Pitulescu ME, Schmidt TS, Bochenek ML, Sakakibara A, Adams S, Davy A, Deutsch U, Luthi U, et al. 1998. Ephrin-B2 controls VEGF-induced angiogenesis and lymphangiogenesis. Nature 465: 483486.

Wang Y, Kaiser MS, Larson JD, Nasevicius A, Clark KJ, Wadman SA, Roberg-Perez SE, Ekker SC, Hackett PB, McGrail M, et al. 2010. Moesin1 and Ve-cadherin are 
required in endothelial cells during in vivo tubulogenesis. Development 137: 3119-3128.

Weinstein B. 2002. Vascular cell biology in vivo: a new piscine paradigm?. Trends Cell Biol 12: 439-445.

Weinstein BM, Stemple DL, Driever W, Fishman MC. 1995 Gridlock, a localized heritable vascular patterning defect in the zebrafish. Nat Med 1: 1143-1147.

Wigle JT, Oliver G. 1999. Proxl function is required for the development of the murine lymphatic system. Cell 98: 769-778.

Wilting J, Papoutsi M, Schneider M, Christ B. 2000. The lymphatic endothelium of the avian wing is of somitic origin. Dev Dyn 217: 271-278.
Wilting J, Aref Y, Huang R, Tomarev SI, Schweigerer L, Christ B, Valasek P, Papoutsi M. 2006. Dual origin of avian lymphatics. Dev Biol 292: 165-173.

Yang Y, Zou L, Wang Y, Xu KS, Zhang JX, Zhang JH. 2007. Axon guidance cue Netrin-1 has dual function in angiogenesis. Cancer Biol Ther 6: 743-748.

Yaniv K, Isogai S, Castranova D, Dye L, Hitomi J, Weinstein BM. 2006. Live imaging of lymphatic development in the zebrafish. Nat Med 12: 711-716.

You LR, Lin FJ, Lee CT, DeMayo FJ, Tsai MJ, Tsai SY. 2005. Suppression of Notch signalling by the COUP-TFII transcription factor regulates vein identity. Nature $\mathbf{4 3 5}$ 98-104. 


\section{$\&_{\mathrm{CSH}}^{\infty} \&$ Cold Spring Harbor

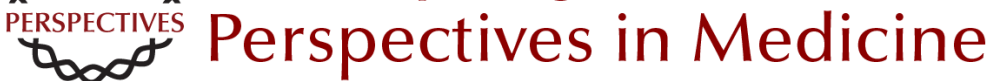

\section{Vascular Development in the Zebrafish}

Aniket V. Gore, Kathryn Monzo, Young R. Cha, Weijun Pan and Brant M. Weinstein

Cold Spring Harb Perspect Med 2012; doi: 10.1101/cshperspect.a006684 originally published online February 7, 2012

\section{Subject Collection Angiogenesis}

Extracellular Matrix Regulation of Vascular Morphogenesis, Maturation, and Stabilization George E. Davis and Scott S. Kemp

Endothelial Cell-Pericyte Interactions in the Pathogenesis of Cerebral Cavernous Malformations (CCMs) Wang Min and Jenny Huanjiao Zhou

Lymphatic Clearance and Pump Function Jerome W. Breslin

Platelets and (Lymph)angiogenesis Harvey G. Roweth and Elisabeth M. Battinelli

Modeling Brain Vasculature Immune Interactions In Vitro Ruth Lyck, Hideaki Nishihara, Sidar Aydin, et al.

Human Endothelial Colony-Forming Cells Juan M. Melero-Martin

\section{The Beauty and Complexity of Blood Vessel} Patterning

Victoria L. Bautch and Yoh-suke Mukouyama

Endothelialitis, Microischemia, and

Intussusceptive Angiogenesis in COVID-19 Steven J. Mentzer, Maximilian Ackermann and Danny Jonigk
Regulation of the Blood-Brain Barrier in Health and Disease Cara C. Rada, Kanako Yuki, Jie Ding, et al.

Targeting Angiogenesis via Resolution of Inflammation

Abigail G. Kelly and Dipak Panigrahy

Notch Signaling in the Vasculature: Angiogenesis and Angiocrine Functions

Sana S. Hasan and Andreas Fischer

Signal Transduction and Gene Regulation in the Endothelium

Michel V. Levesque and Timothy Hla

Buttons and Zippers: Endothelial Junctions in

Lymphatic Vessels

Peter Baluk and Donald M. McDonald

Endothelial Cell Fate Determination: A Top Notch Job in Vascular Decision-Making

L.A. Naiche, Stephanie R. Villa and Jan K. Kitajewski

Leukocyte Trafficking in Lymphatic Vessels Aline Bauer, Hazal Tatliadim and Cornelia Halin

Lymphatic Tissue and Organ Engineering for In Vitro Modeling and In Vivo Regeneration Anna M. Kolarzyk, Gigi Wong and Esak Lee

For additional articles in this collection, see http://perspectivesinmedicine.cshlp.org/cgi/collection/ 